\title{
Efektifitas Gosok Gigi Massal dan Pendidikan Kesehatan Gigi Mulut pada Anak Usia 7-11 Tahun di SDN 174 Kel. Murni Kota Jambi
}

\author{
Vevi Suryenti Putri ${ }^{1}$, Maimaznah ${ }^{2}$ \\ Program Studi S1 Keperawatan, STIKes Baiturrahim Jambi \\ Program Studi D3 Keperawatan, STIKes Baiturrahim Jambi \\ Email : vevisuryentiputri@gmail.com
}

Submitted : 03/09/2020

Accepted: 27/09/2020

Published: 11/01/2021

\begin{abstract}
Abtract
Maintenance of oral health is one way to improve health. The mouth is not just an entry point for food and drink but the function of the mouth is more than that and not many people realize the big role the mouth plays for one's health and well-being.The output target of this activity is the implementation of the School-Age Health Degrees Improvement Program.The method used in this research is observation, counseling and evaluation. The result on brushing teeth properly and correctly Schoolat 174Murni, the children realized that brushing their teeth from an early age was very important, the children were able to brush their teeth properly and correctly even though it was not optimal, so that children had knowledge from an early age about brushing teeth properly and properly. providing support to children in terms of health is very important because it can become a habit for life later.Obtained from counseling on proper and proper tooth brushing at schoo at 174 Murni is that children have realized that brushing their teeth from an early age is very important, children can brush their teeth properly and correctly even though they are not maximized, giving support to In terms of health, children are very important because they can become a habit for their future life.
\end{abstract}

Keywords: children aged 7-11 years, education, mouth, teeth

\begin{abstract}
Abstrak
Pemeliharaan kesehatan gigi dan mulut merupakan salah satu cara meningkatkan kesehatan. Mulut bukan sekedar pintu masuknya makanan dan minuman tetapi fungsi mulut lebih dari itu dan tidak banyak orang menyadari besarnya peranan mulut bagi kesehatan dan kesejahteraan seseorang. Target luaran dari kegiatan ini adalah dilaksanakannya Program Peningkatan Derajat Kesehatan Anak Usia Sekolah. Metode yang digunakan dalam penelitian ini adalah observasi, penyuluhan dan evaluasi. Hasil penyuluhan tentang menggosok gigi yang baik dan benar di SD 174 Kelurahan Murni adalah anak-anak sudah menyadari bahwa menyikat gigi mulai sejak dini sangat penting, anak-anak sudah bisa menggosok gigi dengan baik dan benar walaupun belum maksimal, sehingga anak memiliki pengetahuan sejak dini tentang menggosok gigi dengan benar dan baik.memberi dukungan kepada anak dalam hal kesehatan sangat penting karena bisa menjadi kebiasaan untuk kehidupannya kelak.Diperoleh dari penyuluhan tentang menggosok gigi yang baik dan benar di SD 174 Kelurahan Murni adalah anak-anak sudah menyadari bahwa menyikat gigi mulai sejak dini sangat penting, anak-anak sudah bisa menggosok gigi dengan baik dan benar walaupun belum maksimal, memberi dukungan kepada anak dalam hal kesehatan sangat penting karena bisa menjadi kebiasaan untuk kehidupannya kelak.
\end{abstract}

Kata Kunci : anak usia 7-11tahun, gigi, mulut, pendidikan 


\section{PENDAHULUAN}

Kesehatan merupakan bagian terpenting dalam kehidupan manusia. Baik secara jasmani maupun rohani. Tidak terkecuali anak usia dini, setiap orang tua menginginkan anaknya bisa tumbuh dan berkembang secara optimal, hal ini dapat dicapai jika tubuh mereka sehat. Kesehatan yang perlu diperhatikan selain kesehatan tubuh secara umum, juga kesehatan gigi dan mulut, karena kesehatan gigi dan mulut dapat mempengaruhi kesehatan tubuh secara menyeluruh. Dengan kata lain bahwa kesehatan gigi dan mulut meruapak bagian integral dari kesehatan tubuh secara keseluruhan yang tidak dapat dipisahkan dari kesehatan tubuh secara umum.

Kesehatan gigi dan mulut sangat penting karena gigi dan gusi yang rusak dan tidak terawat akan menyebabkan rasa sakit, gangguan pengunyahan dan dapat mengganggu kesehatan tubuh lainnya. Banyaknya karies, gingivitis dan gigi berjejal harus segera di tangani dan semuanya dapat dicegah. Memelihara kesehatan gigi dan mulut sangat penting untuk memeproleh kesehatan tubuh kita. Khususnya pada anak-anak, karena pada masa anak-anak sangat pentingkarena kondisi gigi susu (gigi decidui) saat ini sangat menentukan keadaan gigi-gigi permanent penggantinya. Untuk mencapai kesehatan gigi dan mulut yang optimal, maka harus dilakukan perawatan secara berkala. Perawatan dapat di mulai dari memperhatikan diet makanan, dan jangan terlalu banyak makanan yang mengandung gula dan makanan yang lengket. Pembersihan plaks dan sisa makanan yang tersisa dengan menyikat gigi, teknik dan caranya jangan sampai merusak struktur gigi dan gusi. Pembersihan karang gigi dan penambalan gigi yang berlubang oleh dokter gigi, serta pencabutan gigi yang sudah tidak bisa dipertahankan lagi dan merupakan fokal infeksi. Kunjungan berkala ke dokter gigi setiap enam bulan sekali baik ada keluhan ataupun tidak ada keluhan.

Membersihkan gigi minimal 2 kali sehari perlu dijalani anak-anak engan harapan ia akan mampu menjaga kesehatan giginya. Pemeliharaan kesehatan gigi dan mulut merupakan salah satu cara meningkatkan kesehatan. Mulut bukan sekedar pintu masuknya makanan dan minuman tetapi fungsi mulut lebih dari itu dan tidak banyak orang menyadari besarnya peranan mulut bagi kesehatan dan kesejahteraan seseorang.

Bila anak memiliki gigi yang tidak sehat dia akan sulit mencerna makanan sehingga proses pertumbuhan si anak akan terganggu. Akibatnya anak akan mudah terserang penyakit. Inilah kemungkinan rembetan masalah gigi anak . sakit gigi membuat malas makan, malas belajar, badan lemah, kurang gizi, banyak dampak lain menyebar keseluruh tubuh.

Gigi merupakan bagian terpenting dalam mulut yang dapat berfungsi untuk makan dan berbicara. Kerusakan gigi merupakan salah satu penyakit yang disebabkan oleh kurangnya kebersihan gigi dan mulut. Anak usia sekolah merupakan usia dimana mereka lebih cenderung untuk memilih makanan yang manis seperti coklat dan permen. Hal ini menjadi faktor utama meninggaktanya anak usia sekolah dengan masalah kerusakan gigi.

Menggosok Gigi adalah Cara yang dilakukan untuk menjaga kesehatan gigi dengan cara menyikatnya. Tujuannya menggosok gigi untuk Membersihkan plak/kotoran dari permukaan gigi,Membersihkan sisa-sisa makanan di dalam mulut, Memelihara kebersihan rongga mulut, Mengurangi kerusakan gigi.

Perawatan gigi dianggap tidak terlalu penting, padahal manfaatnya sangat vital dalam menunjang kesehatan dan penampilan. Tindakan pencegahan terhadap penyakit gigi dan mulut perlu dilakukan agar tidak terjadi gangguan fungsi, aktivitas (belajar dan bekerja), dan penurunan 
produktivitas kerja yang tentunya akan mempengaruhi kualitas hidup. Belajar adalah suatu usaha untuk menguasai segala sesuatu yang berguna untuk hidup. Menurut konsep Eropa, arti belajar ini agak sempit, hanya mencakup menghafal, mengingat dan memproduksi sesuatu yang dipelajari.

Timbulnya masalah kesehatan gigi dan mulut pada seseorang salah satu faktor penyebabnya adalah tingkat pengetahuan. Pengetahuan dipengaruhi oleh faktor internal dan faktor external. Faktor internal terdiri dari usia dan jenis kelamin. Faktor external terdiridari pekerjaan, sumber informasi, pengalaman, sosial budaya, dan lingkungan. Faktor-faktor inilah yang mempengaruhi pengetahuan seseorang.

Faktor-faktor yang mempengaruhi pengetahuan yaitu: faktor internal, faktor eksternal, dan faktor pendekatan belajar.Tingginya angka penyakit gigi dan mulut saat ini sangat dipengaruhi oleh beberapa faktor yang salah satunya adalah faktor perilaku masyarakat yang belum menyadari pentingnya pemeliharaan kesehatan gigi dan mulut.

Kondisi gigi yang baik adalah penting untuk mewujudkan tubuh yang sehat secara keseluruhan termasuk kondisi fisik secara umum, kemampuan untuk mengunyah dan berbicara, penampilan ada hubungan sosial seseorang dengan yang lainnya.

Berdasarkan data yang didapatkan dari hasil tabulasi menunjukkan anak dengan usia 6-12 tahun di RT 16 memiliki kondisi mulut dan gigi berlubang juga hitam sebanyak 19 orang (76\%). Ini menunjukkan bahwa kurangnnya kebersihan mulut dan gigi pada anak SD N 174, Sehingga rumusan masalah yang ditemui adalah banyak anak-anak kurang memperdulikan kesehatannya sendiri, kurang pengetahuan cara menyikat gigi yang benar, anak merasa kegiatan menggosok gigi tidak menyenangkan.oleh sebab itu kelompok perlu mengadakan penyuluhan atau pendidikan kesehatan tentang cara menggosok gigi yang benar untuk mencegah gigi berlubang dan menjaga gigi tetap bersih dan sehat.

Dengan memperhatikan hal-hal tersebut, maka akan dicapai suatu kesehatan gigi dan mulut yang optimal. Dengan demikian akan meningkatkan kesehatan tubuh secara keseluruhan dan akan meningkatkan etos kerja yang lebih baik lagi. Sehingga kesehatan jasmani dan rohani seperti yang diharapkan akan tercapai.

Kegiatan pengabdian ini di fokuskan kepada pentingnya menjaga kesehatan gigi dan mulut, serta bagaimana cara perawatannya. Sasaran penyuluhan ini diberikan kepada anak-anak usia dini di kota Bandung khususnya di SDN 174 Kelurahan Murni. Adapun rumusan masalah dari program penyuluhan ini adalah untuk memberikan pengetahuan, wawasan dan kesadaran dalam hal memelihara serta menjaga kesehatan gigi dan mulut.

Tujuan umum penyuluhan ini berupa penyuluhan pentingnya menjaga kesehatan gigi dan mulut serta bagaimana cara perawatan gigi yang bisa mendukung tumbuh dan kembang sesuai dengan usia yang diharapkan serta memberi pengetahuan tentang kesehatan gigi dan praktik langsung bagaimana cara menggosok gigi yang benar. Melalui kegiatan penyuluhan ini diharapkan dapat menjadi wadah pengamalan ilmu melalui proses pembelajaran langsung.

Melalui kegiatan ini diharapkan anakanak yang terlibat dapat memahami informasi yang baru diperolehnya serta dapat mempraktikkan cara menggosok gigi yang benar guna mendukung tumbuh kembang anak yang bisa dilakukan dari kebiasaan menggosok gigi setiap hari sebelum tidur dan setelah selesai makan.

\section{TARGET DAN LUARAN}

Target luaran berdasarkan kegiatan yang telah disusun dan dilaksanakan sebagai upaya untuk memberikan 
penyuluhan mengenai menggosok gigi yang baik dan benar adalah siswa SD 174 Kelurahan Murni dan target luaran dari kegiatan ini adalah dilaksanakannya Program Peningkatan Derajat Kesehatan Anak Usia Sekolah.

\section{METODE PELAKSANAAN}

Perencanaan kegiatan dimulai dengan survei lapangan oleh tim pengabdian. Survei lapangan dilakukan oleh tim pengabdian pada tanggal 12 Januari 2019. Permasalahan yang ditemukan adalah banyaknya kasus karies gigi yang terjadi pada anak usia sekolah khususnya siswa/siwi di SDN 174 Kelurahan Murni. Solusi kepada pihak guru SDN 174 untuk menyelesaikan masalah tersebut. Solusi yang ditawarkan adalah memberikan pendidikan kesehatan yang dilaksanakan pada bulan Januari- Februari 2019.

Tahapan pelaksanaan kegiatan pengabdian kepada masyarakat ini adalah sebagai berikut:

\section{Persiapan}

a) Menyusun proposal kegiatan pengabdian kepada masyarakat.

b) Pengadaan Poster/media

c) Menyiapkan materi/bahan presentasi tentang kesehatan gigi dan mulut

\section{Pelaksanaan Kegiatan}
a) Perkenalan, diskusi tim serta menjelaskan kegiatan yang akan dilakukan
b) Edukasi pada anak usia sekolah melalui media infocus, poster dan leafleat.
c) Tanya jawab
d) Penutupan

\section{Monitoring dan Evaluasi}

Monitoring dan evaluasi (Monev) dilakukan secara langsung kepada sasaran. Cakupan Monev dalam kegiatan ini meliputi monev perencanaan dan pelaksanaan dan evaluasi hasil.

\section{HASIL DAN PEMBAHASAN}

Kebersihan gigi dan mulut merupakan hal yang sangat penting. Beberapa masalah gigi dan mulut bisa terjadi karena kurangnya mengenal usia. Anak merupakan usia rentan terhadap karies dan penyakit mulut lainnya karena masih memerlukan bantuan dari orang tua maupun keluarga untuk membimbing dalam menjaga kebersihan gigi dan mulutnya begitu pula pada anak berkebutuhan khusus yang memiliki resiko yang sangat tinggi pada masalah kebersihan gigi dan mulutnya karena memiliki keterbatasan dalam dirinya. Anak berkebutuhan khusus merupakan anak yang memiliki keterbatasan mental, fisik dan emosi yang berbeda dengan anak normal. Anak berkebutuhan khusus mengalami gangguan dalam berkembang, baik dari segi fisik maupun mentalnya serta memerlukan pelayanan yang spesifik. Berbeda dengan anak pada umumnya, mereka mengalami hambatan dalam belajar dan perkembangan baik permanen maupun temporer yang disebabkan oleh faktor lingkungan, faktor dalam diri anak sendiri, atau kombinasi keduanya(Indahwati, V., dkk, 2015).

Gigi yang sehat adalah gigi yang bebas karies ataupun gigi yang sudah mendapatkan perawatan yang tepat, sehingga tidak mengganggu fungsinya. Dengan adanya gigi yang sehat maka, fungsi gigi untuk mengunyah maupun untuk fonetik dan estetik dapat berja-lan dengan baik. Kondisi gigi yang sehat harus didukung oleh sehatnya jaringan periodontal, karena jaringan periodontal adalah jaringan pendukung gigi.

Menurut data Riskesdas (Riset Kesehatan Dasar) tahun 2018 persentase penduduk yang mendapatkan konseling perawatan kebersihan gigi dan mulut pada kelompok umur 5 - 9 tahun sebesar 8,3\% dan pada kelompok umur $10-14$ tahun sebesar 5,9\% .

Menurut Emilija, S., dkk (2010), menyebutkan bahwa kebersihan gigi dan mulut serta penyakit periodontal merupakan 
masalah terbesar yang dialami penyandang cacat. Anak berkebutuhan khusus memiliki tingkat kesehatan dan kebersihan gigi dan mulut yang rendah jika dibandingkan dengan anak normal.

Orang tua dalam membina dan membimbing buah hatinya merupakan suatu hal yang sangat vital. Pendidikan yang terima oleh seorang anak, diawali dari para orang tuanya. Pendidikan keluarga yang ditanamkan kepada anak merupakan pondasi dasar pendidikan anak di masamasa yang akan datang. Dengan istilah lain keberhasilan anak khususnya pendidikan, sangat bergantung pada pendidikan yang diberikan oleh orang tuanya dalam lingkungan keluarga (UURI, 2010).

Menurut Hidayat, (2016) bahwa Menyikat gigi adalah cara yang umum dianjurkan untuk membersihkan berbagai kotoran yang melekat pada permukaan gigi dan gusi. Lama menggosok gigi tidak ditentukan, tetapi biasanya dianjurkan maksimal 5 menit (minimal 2 menit), yang penting dilakukan secara sistematis supaya tidak ada bagian-bagian yang terlampaui. Cara yang dianjurkan mulai dari posterior ke anterior pada sisi-sisi rahang bawah dan rahang atas, dan berakhir pada posterior sisi lain. Sedangkan tujuan menyikat gigi adalah membersihkan mulut dari sisa-sisa makanan agar fermentasi sisa makanan tidak berlangsung terlalu lama, sehingga kerusakan gigi dapat terhindari.

Debris adalah sisa makanan yang menempel pada gigi dan gingiva yang dapat dibersihkan secara mekanis. Cara mekanis yang dapat menghilangkan debris diantaranya dengan menyikat gigi dan berkumur. Kegiatan menyikat gigi merupakan salah satu cara yang efektif dan mudah dalam menghilangkan sisa-sisa makanan serta plak baik menggunakan sikat gigi tradisional maupun kayu siwak yang sama-sama mempunyai tujuan membersihkan mulut dari sisa-sisa makanan agar fermentasi sisa makanan tidak berlangsung terlalu lama, sehingga kerusakan gigi dapat terhindari.

Makanan yang menempel pada gigi, seperti permen memerlukan waktu relatif lama untuk membersihkan. Selama waktu inilah, yaitu segera sesudah makan, sebagian besar kerusakan gigi terjadi bakteri. Maka waktu yang ideal untuk menggosok gigi segera setelah makan dan minum.

Para ahli berpendapat bahwa menyikat gigi 2 kali sehari sudah cukup, karena pembersihan sisa makanan kadang-kadang tidak sempurna, dan ada kemungkinan bahwa bila ada yang terlewat pada pagi hari, pada waktu malam hari dapat dibersihkan. Waktu terpenting menyikat gigi adalah yang terakhir malam hari sebelum tidur, karena aliran air ludah tidak seaktif siang hari dimana bakteri berkembang biak dari sisa makanan, menyikat gigi pertama kali dikakukan pagi hari karena bakteri berkumpul dalam mulut. Frekuensi menyikat gigi sebaikan dibersihkan 3 kali dalam sehari, setiap sesudah makan, dan sebelum tidur malam. Dalam praktek anjuran tersebut tidak selalu dapat dilakukan, terutama bila di siang hari seseorang mempunyai kesibukan dalam pekerjaan (Fatarina, 2010).

Sewaktu menyikat gigi harus diingat bahwa sebaiknya arah penyikatan adalah dari gusi ke permukaan gigi, dengan tujuann selain membersihkan gigi juga dapat dilakukan suatu pengurutan yang baik terhadap gusi (Fatarina, 2010). Sebelum dan pada waktu menyikat gigi terdapat beberapa hal yang biasanya dilakukan. Hal ini dilakukan agar dapat lebih mudah dalam membersihkan gigi, yaitu, Membasahi sikat gigi sebelum diberi pasta gigi, berkumur dan melaksanakan penyikatan sampai pasta gigi berbuih (Fatarina, 2010).

Dalam pelaksanaan menyikat gigi yang optimal perlu diperhatikan faktorfaktor yaitu, teknik penyikatan harus dapat membersihkan semua permukaan gigi, gerakan sikat gigi tidak boleh melukai 
jaringan lunak maupun jaringan keras, teknik penyikatan harus sederhana dan mudah dipelajari, teknik harus tersusun dengan baik, sehingga setiap bagian gigi dapat disikat bergantian dan tidak ada daerah yang terlewatkan (Manson \& Eley, 1993).

Karies gigi adalah penyakit yang disebabkan oleh banyak faktor di antaranya terjadi interaksi dari empat faktor utama yang ada di dalam mulut yaitu 1) host (gigi dan saliva). 2) microorganisms (plak),substrat (diet karbohidrat), 4)waktu.Faktor lain sebagai faktor predisposisi adalah a) Jenis kelamin, b) tingkat pendidikan, c) tingkat ekonomi, dan d) perilaku. Karies gigi merupakan penyakit kronis yang bersifat irreversibel di mana kerusakan pada gigi tidak dapat sembuh seperti luka jaringan, bila

dibiarkan berlanjut akan menyebabkan kehilangan gigi dan kemudian akan mempengaruhi proses pengunyahan, fungsi bicara dan penampilan estetis.

Memelihara kesehatan gigi anak usia sekolah dilakukan dengan cara memberikan pemahaman tentang kebersihan gigi dan mulut. Oleh karena itu, kepedulian akan kesehatan gigi harus ditanamkan sejak dini, sehingga menghindarkan anak dari masalah penyakit gigi. Seringkali anak lalai untuk menjaga kesehatan gigi yang disebabkan oleh perilaku anak yang negatif. Namun demikian, menanamkan kesadaran anak akan pentingnya kebersihan gigi memang tidak bisa dilakukan secara instan, bahkan butuh kesabaran ekstra. Bila hal ini dilakukan, maka kesadaran menjaga kesehatan gigi ini akan menjadi kebiasaan sampai anak menjadi dewasa.

Hal-hal yang menjadi hambatan dalam membersihkan gigi adalah 1) Anak tidak terbiasa dengan kegiatan menyikat gigi sehingga dianggap sebagai hal yang menakutkan bahkan menyakitkan, 2) Trauma yang diakibatkan penyikatan gigi yang dipaksa oleh orang tua, 3) Pemilihan pasta gigi maupun sikat gigi yang tidak tepatsehingga anak tidak merasa nyaman serta mengakibatkan muntah. untuk itu, dalam upaya mengatasi dan mencegah terjadinya penyakit gigi dan mulut pada anak dilakukan pendidikan kesehatan inasyarakat untuk perilaku pencegahan penyakit gigi dan mulut melalui penyuluhan. Tujuannya adalah agar terjadi perubahan dalam perilaku pada anak usia sekolah imtuk dapat hidup sehat.

Prinsip-prinsip dalam menyikat gigi menurut Madan, dkk., (2011) yaitu, pegangan sikat harus dipegang dengan kuat tetapi jangan terlalu kuat karena akan melelahkan tangan dan pergelangan tangan, hindari pandangan ke bawah bidang, metode menyikat gigi yang benar harus dianjurkan tergantung pertumbuhan gigi dan keadaan gusi, dianjurkan untuk menggunakan jenis sikat gigi yang lembut, pertengahan atau keras (sikat gigi yang lembut bulunya berdiamter $0,2 \mathrm{~mm}$, pertengahan $0,3 \mathrm{~mm}$, dan keras $0,4 \mathrm{~mm}$ ), tergantung pada gusi, Keefektifan dalam menyikat gigi juga tergantung pada sikat. Warna bulu tidak efektif untuk membersihkan, sikat harus diganti. Warna penunjuk bulu sikat gigi dianjurkan yang dapat berubah warna, jadi apabila bulu sikat sudah tidak efektif lagi maka warna bulu sikat akan berubah warna.

Usaha promosi kesehatan dengan menggunakan metoda penyuluhan kesehatan gigi dengan menggunakan poster dan leaflet bertujuan agar terjadi perubahan dalam perilaku di bidang kesehatan gigi dan mulut pada anak, dengan penekanan pada perilaku saat ini dan yang akan datang. Dikemukakan oleh Notoatmojo (2010) bahwa perilaku kesehatan sebagai respons seseorang terhadap stimulus yang berkaitan dengan penyakit. Lain halnya dengan Gochman (1998), yang menjelaskan bahwa perilaku atau sifat seseorang seperti harapan, keyakinan, presepsi, dan elemen kognitif lainnya mempengaruhi perilaku kesehatan. 
Pendidikan kesehatan gigi adalah suatu upaya atau kegiatan untuk menyampaikan pesan mengenai kesehatan gigi kepada anak sekolah kelompok/individu dengan harapan mereka dapat memperoleh pengalaman tentang kesehatan gigi yang lebih baik, dan akhimya diharapkan pengetahuan tersebut, dapat mempengaruhi perubahan perilaku mereka. Perubahan perilaku yang dimaksud adalah perilaku yang tidak menguntungkan terhadap kesehatan giginya. Perubahan perilaku ini juga yang menjadi tujuan dari pendidikan secara umum pendidikan kesehatan gigi membutuhkan kesungguhan dalam pengetahuannya, sehingga peran pemulihan strategi dalam merencanakan pendidikan kesehatan yang tepat dan sesuai dengan kebutuhan. Diharapkan dengan pembinaan penyuluhan kesehatan.

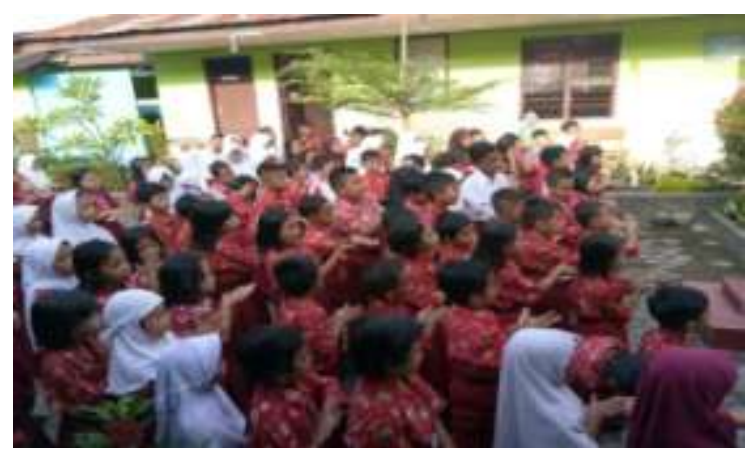

Gambar 1. Siswa memperhatikan materi yang disampaikan.

Dari hasil penyuluhan tentang menggosok gigi yang baik dan benar di SD 174 Kelurahan Murni telah mengubah dan menambah pengetahuan atau pemahaman dari sebagian anak yang ikut penyuluhan, dengan bisa menyebutkan Menjelaskan tentang pengertian gosok gigi, menjelaskan tentang manfaat gosok gigi, menjelaskan tentang waktu yang tepat untuk menggosok gigi, menjelaskan akibat bila tidak menggosok gigi, menjelaskan cara menggosok gigi dengan baik dan benar.

Dari hasil evaluasi didapatkan bahwa pada tahap persiapan acara penyuluhan dan peserta dapat hadir sesuai dengan rencana, tempat, media serta alat-ala tuntuk penyuluhan tersedia sesuai rencana dan penyebaran undangan dilakukan 1 hari sebelum penyuluhan berlangsung. Kemudian untuk evaluasi proses didapatkan hasil bahwa jumlah peserta yang hadir (80 $\%$ ) berjumlah 110 dari 130 siswa, kelas 1, 3, 4, 5, dan 6. Kelas 2 tidak hadir karena siswa masuk siang, tempat sesuai dengan yang ada dalam pre planning dan SAP yaitu SDN 174 kel. Murni, peserta kurang berperan aktif dalam jalannya diskusi, keaktifan peserta bertanya hanya $30 \%$, pelaksanaan kegiatan tidak sesuai dengan waktu yang di rencanakan, seharusnya pelaksanaan kegiatan dilakukan pukul 07.00 WIB Karena ada beberapa kendala sehingga penyuluhan berlangsung pada pukul 07.30, waktu dalam jalannya penyuluhan tidak sesuai dengan SAP. Dalam SAP penyuluhan akan dilaksanakan sekitar 35 menit, sedangkan dalam proses nya penyuluhan berlangsung 45 menit. moderator yang tertulis di dalam SAP tidak sesuai dengan proses pelaksanaan penyuluhan karena adanya keterlambatan saat dating ketempat penyuluhan, peserta penyuluhan mengikuti kegiatan dari awal sampai akhir dan post test yang dilakukan tidak secara tertulis namun secara lisan.

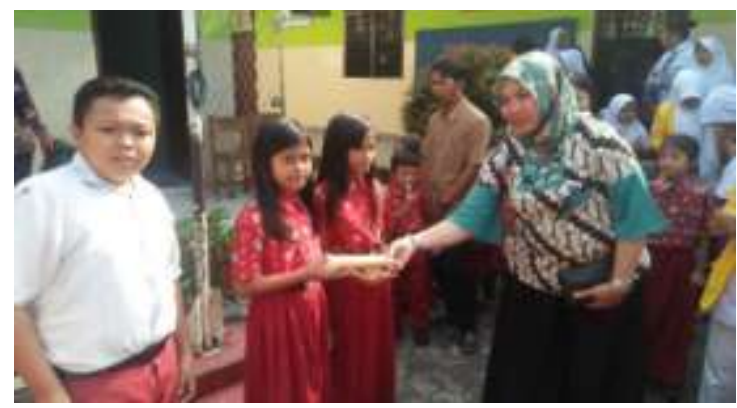

Gambar 2. Memberikan bingkisan di akhir sesi pengabmas.

Sehingga evaluasi hasil dari materi yang telah disampaikan saat siswa mengikuti lomba menggosok gigi adalah siswa kelas 1, 3, 4, 5, dan 6 bisa memperagakan cara menggosok gigi dan didapatkan pemenang sebanyak 3 orang 
pada tiap kelas, post test yang dilakukan tidak secara tertulis namun secara lisan, dan siswa/I SDN 174 Kel. Murni mampu menjawab pertanyaan yang diajukan oleh juri pada lomba menggosok gigi.

Kebersihan gigi dan mulut merupakan tindakan yang bertujuan untuk membersihkan dan menyegarkan gigi dan mulut. Tindakan pembersihan gigi dan mulut dapat mencegah penularan penyakit melalui mulut memperbaiki fungsi sistem pengunyahan, serta mencegah penyakit gigi dan mulut seperti penyakit pada gigidan gusi. adalah anak-anak sudah menyadari bahwa menyikat gigi mulai sejak dini sangat penting, anak-anak sudah bisa menggosok gigi dengan baik dan benar walaupun belum maksimal, sehingga anak memiliki pengetahuan sejak dini tentang menggosok gigi dengan benar dan baik.memberi dukungan kepada anak dalam hal kesehatan sangat penting karena bisa menjadi kebiasaan untuk kehidupannya kelak, Dengan adanya gigi yang sehat maka, fungsi gigi untuk mengunyah maupun untuk fonetik dan estetik dapat berja-lan dengan baik. Kondisi gigi yang sehat harus didukung oleh sehatnya jaringan periodontal, karena jaringan periodontal adalah jaringan pendukung gigi.

Tingkat pengetahuan orang tua yang tinggi tidak menjamin kebersihan gigi dan mulut menjadi baik apabila tidak diterapkan atau dilakukan dalam kehidupan seharihari, begitu pula tingkat pengetahuan orang tua yang kurang akan mempengaruhi tindakan yang kurang tepat dan akan mempengaruhi kebersihan gigi dan mulut anak. Hal ini sesuai dengan teori Notoatmodjo, S., (2018) bahwa perilaku yang didasari oleh pengetahuan akan lebih langgeng daripada perilaku yang tidak didasari oleh pengetahuan. Seperti penelitian yang telah dilakukan oleh (Ningsih, C., \& Kustantiningtyastuti, D. 2016) bahwa tingkat pengetahuan seseorang dapat mempengaruhi status kebersihan gigi dan mulut anak, hal ini ditunjukkan dengan hasil penelitian yang sudah dilakukan. Peran orang tua sangatlah penting untuk meningkatkan status kebersihan gigi dan mulut anak dan merupakan salah satu upaya dalam pemeliharaan kebersihan gigi dan mulut anak.

Pengetahuan yang dimiliki orang tua akan menjadikan tepat atau tidaknya tindakan dalam hal memelihara kebersihan gigi dan mulut anaknya, karena orang tua tersebut mempraktekkan dalam hal memelihara kebersihan gigi dan mulut sesuai dengan pengetahuan yang dimiliki orang tua. Menurut (Suresh, B.S., dkk, 2010) dimana peran orang tua terutama seorang ibu terhadap bagaimana menjaga kesehatan gigi dan mulut sangatlah penting dalam mendasari terbentuknya perilaku yang mendukung kebersihan gigi dan mulut anaknya sehingga kesehatan gigi dan mulut anak dapat menjadi lebih baik.

Menurut Ilyas dan Putri (2012) dalam penelitiannya menjelaskan bahwa kelompok usia 8-11 tahun merupakan usia kelompok rentan terhadap terjadinya masalah kesehatan gigi dan mulut karena pada usia ini mempunyai sifat khusus yaitu transisi pergantian gigi susu ke gigi permanen. Hasil penelitian yang dilakukan Azwindri (2013) menjelaskan bahwa semakin tinggi tingkat kelas anak semakin tinggi pula usia mereka sehingga tingkat pengetahuan yang didapatkan mengenai kesehatan gigi dan mulut semakin tinggi.

Menurut Herijulianti, Indriani, dan Artini (2001) mengemukakan bahwa usia hubungannya erat dengan tingkat pengetahuan mampu dalam memelihara kesehatan gigi dengan kedewasaan yang dimiliki dan teori Putra dkk (2014) bahwa pada tahap perkembangan usia sekolah anak mulai berfikir logis dan terarah sertamampu berfikir menurut sudut pandang orang lain. Hal ini menjadi dasaruntuk guru maupun orang tua untuk membentuk kepribadian yang baik untuk anak. 
Perilaku meningkatkan kesehatan gigi dan mulut dipengaruhi oleh perbedaan psikologis anak. Hal ini adanya perbedaan kondisi gen. Menurut penelitian Mirani (2009) yang menyatakan laki-laki sedikit lebih agresif dibandingkan perempuan karena pada laki-laki terdapat gen Sex Determining Region $Y$ (SRY). Gen ini diduga menyebabkan anak laki-laki memiliki tingkat pengendalian emosi lebih rendah dibandingkan anak perempuan. Selain itu, psikologis anak juga dapat dipengaruhi oleh adanya sibling.

\section{KESIMPULAN DAN SARAN 1 Kesimpulan}

Kesimpulan yang diperoleh dari penyuluhan tentang menggosok gigi yang baik dan benar di SD 174 Kelurahan Murni adalah anak-anak sudah menyadari bahwa menyikat gigi mulai sejak dini sangat pentingdanmenggosok gigi dengan baik dan benar walaupun belum maksimal

\section{Saran}

Perlu diadakannya program pengabdian masyarakat tentang menggosok gigi bukan hanya ditingkat sekolah dasar saja tetapi tingkat yang lebih tinggi lagi agar cakupan pesertanya bertambah banyak

\section{UCAPAN TERIMAKASIH}

Terimakasih yang tak terhingga kepada Sekolah Tinggi Ilmu Kesehatan Baiturrahim Jambi yang memberikan kemudahan dalam pelaksanaan penelitian ini. Selain itu penulis juga mengucapkan terimaksih kepada ketua RT. 16 Kelurahan Murni, Kota Jambi dan penulis juga mengucapkan terimakasih kepada msyarakat dan SDN 175 Kelurahan Murni, Kota Jambi karena telah senang hati menerima dan membantu proses pengabdian ini sehingga kegiatan ini bisa terlaksana dan berjalan lancar.

\section{DAFTAR PUSTAKA}

Azwindri.(2013).Faktor-faktor yang mempengaruhi terjadinya karies gigi pada anak di Sekolah Dasar Ngebel Kecamatan Kasihan Kabupaten Bantul Yogyakarta. STIKES Alma Ata.

Darmono, A., 2015, "Peran Orang Tua Dalam Pendidikan Anak Berkebutuhan Khusus". Jurnal Studi Islam dan Sosial.

Desiningrum, D.R. (2016). Psikologi Anak Berkebutuhan Khusus. Yogyakarta:Psikosain.

Emilija, S., Nakova, M., Nikolovska,V.R., Ristoska, S., 2010, "Tooth brushing intervention programe among children with mental handicap". Journal CitationReports. 111, (5). Indahwati, V., Mantik, M.F.J.,

Gunawan, P.N. (2015) "Perbandingan Status Kebersihan Gigi dan Mulut pada Anak Berkebutuhan Khusus Slb-B Dan Slb-C Kota Tomohon". e-GIGI. 3, (2), 361-362.

Notoatmodjo, S., (2018). MetodologiPenelitian Kesehatan. Jakarta: RinekaCipta.

Ningsih, C., \& Kustantiningtyastuti, D. (2016). "Hubungan Tingkat Pengetahuan Orang Tua dengan Status Kebersihan Gigi dan Mulut Anak Tuna Rungu Usia 9-12 Tahun Di SLB Kota Padang”. AndalasDental Journal. 4, (2), 78-88.

Putra, D. S. H., Hendro, P., Hadi, S.

M., Fahmi, I., Hizar, C. A., \&Alfian. (2014). Keperawatan Anak \& Tumbuh Kembang (Pengkajian dan engukuran). Yogyakarta: Nuha Medika.

Riset Kesehatan Dasar (2018) tentang Prevalensi Karies, Karies Akar dan Periodontitis menurut Karakteristik

Undang-Undang Kesehatan RI nomor 36Tahun 2010 tentang kesehatan. Tambahan Lembaran Negara Republik Indonesia Nomor 5063. 